\title{
Impact of Event Management Outcome in a Students Employability Perception
}

\author{
Elvir Čizmić, Senad Softić \\ School of Economics and Business Sarajevo, Sarajevo University, Bosnia and Herzegovina
}

Copyright(C2018 by authors, all rights reserved. Authors agree that this article remains permanently open access under the terms of the Creative Commons Attribution License 4.0 International License

\begin{abstract}
The aim of the research is to determine how the Career and Entrepreneurship Opportunities Conference, as a unique combination of academic and student's entrepreneurship, content affects the students' personality development in context of their employability perception. The study was used a qualitative approach for problem introduction and mostly quantitative approach to research. Data collection was conducted by using LimeSurvey application with lasting of sixty days for sample of students population that have been participated to the conference, with the use of a special questionnaire created for this study. The populations covered by this research are all participants of the Career and Entrepreneurship Opportunities Conference in the period of 2014-2016 and it makes more than five thousand students. This research is aimed to present effects of nonconventional ways of matching between higher-education institutions and labor market in Bosnia and Herzegovina in sense of students' employability as most important matching component, using as well some good practical evidences connected to the Career and Entrepreneurship Opportunities Conference content, activities and effects.
\end{abstract}

Keywords Academic Entrepreneurship, Event Management, Students Conferences, Students Personality Development, Employability Perception

\section{Introduction}

The success of educational institutions, and in particular of higher-education institutions, in the context of the modern business environment that generates continuous transformations in business structure, depends on the intensity of development, sharing and generation of knowledge, on application of the principle of intrapreneurship and on utilization of knowledge in the educational institution, which may, to a certain extent, be achieved through effective event management and entrepreneurial orientation. Event management is a specific management discipline focused on planning, organization, staffing, coordination and oversight of various events in various industries, which may include the education sector, health services industry, information technology industry, tourism or any other industry or sector. Events are a dynamic social and organizational lateral connection that simultaneously initiates multiple activities and content, with special effects and impact on clients, organizations and associations, so it is important to assess the impact of the contents of events and activities on the behavior of clients, i.e. participants in various events, such as business and scientific conferences and other events. Ultimately, the capacity of modern higher-education institutions, as organizations of a particular nature, to achieve not only their current objectives, but also to generate and comprehensive future possibilities, in the context of future demands, will depend on their ability to create and deliver extraordinary values and unconventional content. This essential aptitude will ensure higher employability of enrolled individuals and delivery of content whose application may lead to higher levels of performance of organizations, i.e. various employers, as clients. This paper presents the core activities implemented by the Entrepreneurship and Knowledge Management Center of the School of Economics at the Sarajevo University, and particularly for the Career and Entrepreneurship Opportunities Conference, as a distinct event, aimed to bring about a shift in young people's attitudes towards entrepreneurial thinking and behavior, through active presence and participation in various activities in the education system that may equip them with supplementary practical knowledge, capabilities and skills. This research describes a fundamental enquiry into the core activities and effects of such activities on participants, in the sense of knowledge, innovativeness, creativity, motivation and self-employment of conference participants, primarily students, in the process of higher-education in Bosnia and Herzegovina. The objective of this paper is to demonstrate the effects of unconventional models of 
linking higher-education institutions and the labor market in Bosnia and Herzegovina in the context of students' employability by application of good practices connected with the CEO Student Conference as a business practice phenomenon that has been very well received. CEO student conference is specific according to its content because within it there are a lot of different activities such as start-up challenge, coffee with, real business speaker conference, business planning trainings, crowd funding activities, mentoring and coaching activities, student internship and other activities aimed to develop students skills and wake up their talent and creative potential. CEO is not some classic conference because activities of CEO conference are lasting during the whole of the year. Of course influence of CEO conference is a continual process by using social networks special group and following CEO speakers on YouTube. It means that CEO conference involves business community representatives taking part through two roles such as sponsors from one side and speakers form the other side and academic community in sense of students training in different business area on a volunteer base. This student conference encompassed a lot of different stake holders including some government institution support and final product of all activities is to obtain higher level of employability and self-employability of the students.

\section{Literature Review and Theoretical Framework}

Entrepreneurship is considered as one of the most important factors that contribute to economic and business development, and as such it generates multiple benefits for society, whether in terms of individual shifts towards entrepreneurial orientation from the standpoint of management, economy or a certain socio-psychological phenomenon related to deliberation and behavior of each individual. Entrepreneurial action generates innovation, creates new jobs, develops human potential and meets novel needs of clients, according to European Commission Reports. The European Union sought to respond to this challenge through its short-term policies, but ordinary entrepreneurial infrastructure, an assortment of incentives, grants and elimination of bureaucratic barriers failed to produce expected, i.e. sufficiently high, impact on creation, growth and development of new enterprises. This situation led to the realization that there is a need to develop a new approach, with the main objective to permit as many people to become entrepreneurs, but still only a small fraction of working age population got involved in entrepreneurial initiatives [1]. This fact pointed to the need to redirect the focus of action and research and prompted researchers to use socio-cognitive models and theories to identify those factors that had impact on entrepreneurial intention, i.e. on the decision to start a new business [2] and to shift the focus on the segment of infrastructure whose activation may have a considerable impact on the ways of deliberation and personal behavior, and that is the education sector [3].

The individual decision to start a business has long been seen as the fundamental step in the startup process [4]. Realistically, the decision to launch an entrepreneurial initiative may be considered as a mature voluntary and conscious process, which takes place over time, and define the relationship between attitude and behavioral intention [5]. In this regard, entrepreneurial intent would be the first step in sometimes long-lasting process of development of an entrepreneurial undertaking [6]. Viewed from this perspective, the intent of launching a startup, i.e. the socio-psychological segments of the personal profile of the person may be considered the best behavioral predictor, in the context of employability and self-employability [7]. On a related note, the reform trends in the domain of science and research have intensified in recent years, particularly regarding the effects of application of entrepreneurial principles on functioning of scientific and research organizations. Linking scientists, students and entrepreneurs, technology transfers and commercialization of knowledge had a positive impact on innovativeness of United States of America and certain European economies and this task has been approached in a systemic fashion. The above activities emerged as an outcome of the recognition of need for a profound conceptual transformation of the functioning of universities and research institutes and of their correlation with the economy and the business sector. As a distinct, change-driving social category, students are seen as the essential link on this path. Introduction of a new conceptual framework for functioning of universities, i.e. development of fourth-generation universities, is seen as a solution to the above problem. This solution should integrate the three segments of education, scientific research, and commercialization of new businesses and technologies, as well as application of such models that would combine humans, machines and digital technologies in all research, education, business and overall socio-economic processes.

Methodologies used to date to study entrepreneurial intent have constantly evolved in recent years. After personal characteristics and traits that may be related to entrepreneurial activity and motivation, researchers focused on demographic variables, such as age, gender, origin, religion, culture, education type and level, work experience. Nevertheless, although permitting identification of significant connections between certain traits and demographic characteristics, both of these courses of research encountered major criticism, both from the methodological and theoretic standpoint, which emphasized inadequacy of general individual characteristics in predicting entrepreneurial behavior [8]. As a result, since mid-1990s, researchers increasingly emphasized the importance of cognitive factors in studying 
of entrepreneurial intentions. Taking into account that starting a new business requires certain time, including considerable planning and cognitive thinking, entrepreneurial behavior may be viewed as a form of planning behavior directed to self-employability, which is ideally suited by intent models between student populations [9]. In this regard, entrepreneurial intent would be the first and crucial step in origination of an entrepreneurial behavior [10]. Several models have been used to try to explain entrepreneurial intent, such as Shapiro's model of entrepreneurial event, entrepreneurial idea implementation model application and the maximization of expected utility model. While the above models represent a significant advance in the research into entrepreneurial intent, they have not been as influential as well established Theory of Planned Behavior. Unlike other models, the Theory of Planned Behavior offers a consistent and generally applicable theoretical framework, which permits comprehension and prediction of entrepreneurial intent and takes into account not only personal, but also social, factors [11].

According to the Theory of Planned Behavior, there are three factors that explain entrepreneurial intent. The first factor, attitude toward start-up, relates to the level of positive or negative personal values an individual attitudes about becoming an entrepreneur [12]. The subjective norm is the second factor, defined as the way an individual experience social pressure to behave (or not) in an entrepreneurial fashion. In essence, the subjective norm relates to the individual perception whether relevant persons (such as, for instance, parents, spouses, children etc.) would or would not support his or her decision about becoming an entrepreneur. The third factor, perceived behavioral control, relates to the individual perception whether it is easy or difficult for him/her to become an entrepreneur. This factor greatly resembles the self-efficiency concept and the concept of perceived feasibility in that all three concepts relate to the sense that it is possible to behave in a way necessary to launch an entrepreneurial undertaking [13]. In general terms, major psychological characteristics in the literature that are related to entrepreneurship are the internal locus of control, propensity for risk, self-confidence, striving for achievement, tolerance of uncertainty and innovativeness. Although criticized in the past, personal traits continue to attract significant attention in the study of entrepreneurial intent [14]. There are numerous studies that examine influence of personal traits on entrepreneurial intent and some of the studied traits include: risk perception, locus of control, innovativeness, creativity, emotional intelligence, etc. On the other hand, researchers believe that particular attention should be paid to development of skills, such as recognition of opportunities, creativity, problem solving, leadership, communication skills, innovativeness and networking, because all of these are necessary for entrepreneurial success. For all the above reasons, the study of the factors that influence entrepreneurial intent is of crucial importance for the overall study of entrepreneurship especial among students of business schools. The famous entrepreneurship thinker, Schumpeter, believed that innovativeness was the fundamental aspect of entrepreneurship and the crucial entrepreneurial characteristic and explains innovativeness as competence to create some new approach of doing business using new combination of resources and knowledge. Some of the authors underlined elements such as capability of doing business in qualitatively different way, readiness for taking risk, capability of noticing opportunities for doing business, personal mental profile of entrepreneur, cultural and spiritual aspects, tradition, family heritage, innovativeness, creativity, conceptual thinking competence and striving for achievement. [15] Additionally, social cognitive aspects, demographic aspects such as age and gender, self-employability orientation, independency orientation and other features can take very important part in entrepreneurship orientation researching [16]. All earlier mentioned aspects have to take in consideration during some modern entrepreneurship research conducting, taking in consideration main recognized predictors and some indicators as a control aspect of research.

\section{Research Methodology and Hypothetical Framework}

On the basis of previous theoretical observations, it is possible to distinguish six, and more recently seven, or eight, basic types of entrepreneurship. In this sense, entrepreneurial theory and practice recognizes individual entrepreneurship, group entrepreneurship, corporate (internal) entrepreneurship, family entrepreneurship, female entrepreneurship, social entrepreneurship, and academic entrepreneurship, including the phenomenon of student entrepreneurship [17]. Each kind of entrepreneurship may be explained in such a way that the context of its emergence and the basis for its differentiation may be comprehended, in view of the fact that entrepreneurial philosophy, which reflects a certain manner of behavior and thought constitutes a fundamental basis for all above type of entrepreneurship. Pursuant to the principle of the theory of planned behavior, it is known that positions permit anticipation of planned, i.e. intended behavior, in this case, that of young people, students who take part in the CEO Conference of the Sarajevo School of Economics. According to this theory, the best predictors of behavior are behavioral intentions in various segments related to personal attitudes, social norms and innovativeness of young people in the context of their entrepreneurial orientation that may be interpreted as their employability. Therefore, the stronger an intention to perform a certain behavior is, the fulfillment of a stated intention that is the subject of this research more likely. 
The research was organized by utilizing the LimeSurvay package to generate research questionnaires and collect research data, in combination with collection of assorted reports related to online activities of the CEO Conference as a student-driven educational and business phenomenon. The questionnaire is based on valid items and constructs that are defined by entrepreneurial intention model. The data were collected online through the aforementioned tool, which was shared through social networks and professional CEO conference profile network with the students who followed the events related to the content and activities of the CEO Conference and who have been involved in its various programs throughout the region. During research conducting, in call for questionnaire fulfilling, research population was defined and limited on students that participate in organizing or as audiences of the conference aiming to get relevant date based on real feel within real business life. The students are coming from all state universities in Bosnia and Herzegovina and main universities from neighbor countries such as Zagreb University from Croatia, Belgrade University from Serbia, Podgorica University from Montenegro. Most of them are coming from business faculties of the universities mentioned above but also from other scientific areas. The importance of CEO conference that has been originally designed by the Sarajevo University School of Economics and Business can be understood because all other universities accepted this student's conference as their own.

During this period, the research population numbered over 5.000 young persons, with each person receiving the online questionnaire, so that all members of the population had the same opportunity to become part of the sample, but within approximately two months 636 respondents filled in the questionnaire, with 349 questionnaires completed, so that the data contained in them provided a sound basis for analysis. Naturally, the population in question doubled in size between the time when the technical and statistical research was conducted and the completion of this paper. The research was conducted between 11th January and 22nd March 2016, which means that it lasted 60-70 days, with on average around ten respondents filling in the questionnaire every day. When everything else is taken into account, this sample may be qualified as a sample of convenience, as it is not completely random in character, and this fact may constitute a certain limitation of this research. Notwithstanding the above, the organization and the research process ensured a sufficient level of randomness and representation, since there was not particular targeted prompting for filling the questionnaire, instead respondents at random filled it in accordance with their behavioral patterns and individual preferences for taking part in particular activities.

The main research hypothesis is based on the assumption that the contents and activities of the CEO Conference of the Sarajevo University-Sarajevo School of Economics have a positive impact on the development of entrepreneurial potential, and employability of conference participants. In this form, this core hypothesis may serve as a platform for formulation of auxiliary hypotheses, intended for additional components of research, in order to provide supporting evidence for the core hypothesis, as follows:

1. The contents and activities of the CEO Conference shape personal attitudes of participants, which has a significant impact on their entrepreneurial orientation and employability.

2. The contents and activities of the CEO Conference shape participants' social norms, which has a significant impact on their entrepreneurial orientation and employability.

3. The contents and activities of the CEO Conference shape participants' capacity for innovation, which has a significant impact on their entrepreneurial orientation and employability.

In line with the postulated problem framework, the core purpose of the research was to empirically study students' entrepreneurial intentions, i.e. their perception of employability and self-employability, applying an adjusted model based on Icek Ajzen's Theory of Planned Behavior. Three basic factors that are taken into account in this case are: students' personal attitudes, subjective norms and students' innovativeness in the context of their effects on the perception of employability of the participants in the CEO Conference, who constitute a representative group of entrepreneurially minded young people in Bosnia and Herzegovina.

Preliminary research related to the works of authors such as Bandura and Ajzen, and subsequently Krueger, which include attitudes, behavior, as well as entrepreneurial aspects and employability, allowed identification of the models applicable to the desired study into the event management, i.e. into the phenomenon of the CEO Conference and its shaping and influence on participants' behavior [18]. After a review of key articles and concepts, the model for the research in question was developed, which served as the basis for designing a questionnaire adapted for the specific research purpose. The survey questionnaire was designed to collect all relevant data required for the research process based on an a priori postulated model. The research was conducted very effectively and in technical terms it took around two months, because the response was rather good and swift, since the researched population, including CEO Conference participants, is highly IT literate and, as it turned out, very responsive, which significantly facilitated the technical part of research and at the outset permitted a formulation of an outline of future outcomes of the research process. The sample was calculated in the following manner: the values of median and variance were tested through preliminary research, with application of the 
assumptions of the Central Limit Theorem, and the desired reliability at th .95 level and the margin of error at .5 level, which made it possible to calculate the necessary number of participants to obtain a representative sample as 3.33\% (166 participants). In the actual research, the coverage was around 7\% (349 participants) of the researched population, which provided for a rather high level of sample representativeness, sufficient even if the statistical population numbered over 10,000 units. The questionnaire has been distributed to the entire population for filling in, and respondents had two months to randomly fill in the questionnaire without targeted invitations by anyone, which satisfies the assumption of randomness of persons who provided responses, so the sample in question may still be seen as random. The research population, i.e. the number of students, who participated in the CEO Conference at the time, numbered around 5,000 persons, while additional 5,000 persons took part in the new CEO Conference 2017/18 cycle, which demonstrates the swift expansion of the CEO Conference of $100 \%$ in the last year alone, since the study covers the CEO Conference 2015/16, we note that this research could be taken for CEO conference, in general.

\section{Research Assumptions}

The value of the Cronbach's Alpha coefficient for each item was over .90 , but also for each construct/section integrally, which indicates high reliability of the questions from the used questionnaire. The Cronbach's Alpha coefficient for each construct in the entire questionnaire is .90 or more, which may be considered as a highly acceptable, i.e. excellent score. After the data were collected, they were entered into a SPSS database, and as a first step were tested for internal consistency of each section/construct that measure prediction and criteria variables related to the perception of the participants at the CEO Conference of the Sarajevo University-Sarajevo School of Economics, together with the calculation of the Cronbach's Alpha coefficient, as shown in the table below.

Table 1. Cronbach Alpha coefficients for each construct/section

\begin{tabular}{|c|c|}
\hline Construct/Section: & Cronbach's Alpha \\
\hline PA - Personal attitudes & .909 \\
\hline SN - Social norms & .915 \\
\hline I - Innovativeness & .900 \\
\hline E - Employability & .906 \\
\hline
\end{tabular}

Looking at the detailed analysis, one finds that some questions knower the Cronbach's Alpha value negligibly, but such questions are negligibly few and are not related to key constructs targeted in the research model. As they are negligible, it is not necessary to exclude them from further analysis. According to the assumptions of the Central Limit Theorem, the parametric techniques and test were applied, regardless of a slight skewness of the distribution to the right for every variable of the constructed model. Normality analysis of the distribution of each variable/construct is shown in tabular form and in graphs that reveal that not every variable has fully normal distribution but, in the context of the assumption of the Central Limit Theorem, it may be considered as relevant normal distribution and parametric tests may be used in the research, while normality analysis is not even necessary for simplified research platforms of this kind.

Naturally, the normality assumption may be derived from the very framework of descriptive statistics, because the measurements of the central tendency (arithmetic mean, mode, median) do not significantly deviate from each other, while skewness and symmetry do not entirely fit the standard normal curve. The correlation and regression methods were used in this study to examine the links and mutual influences between various constructs by proving chosen assumptions concerning the influence of particular independent variables on the model's dependent variable, i.e. of particular predictor variables on the criterion variable, as this is not a classical experiment.

\section{Measurement of Influence of CEO Conference on Participants' Perception of Employability}

The research that was carried out aimed to identify the links that exist between various variables, i.e. performance measurements, with the objective to find ways to increase students' perceived employability competence effectively and efficiently. For the reasons stated above, an adjusted model developed on the platform of the Theory of Planned Behavior was selected as the framework for the research model, with assumption of causal relationships between the predictor variables and the criterion variable. At the outset, it is worth noting that the research model included the study of performance measurements that, directly or indirectly, impact students' employability competence and thereby achievement of students' set goals and plans. In this sense, students' personal attitudes (PA), perceptions of social norms (SN), and their innovativeness (I) are taken as predictor variables (independent variables in the case of experimentation), while the students' perceived employability (E) is taken as the criterion variable (dependent variable in the case of experimentation). In social and sociological research, using the terms 'predictor' and 'criterion' to designate variables is more appropriate, and these terms have been applied in this case. Next we first examined correlation (existence of a link) and regression (causality direction of the link, i.e. influence) between particular predictor variables and the criterion variable. Testing of the correlation between various variables permitted detection of strong links of each predictor variable with the criterion variable and, in 
combination with the analysis of the dispersion diagram it is possible to detect the presence of a positive correlation between the predictor and criterion variables, as shown in the following tables and graphs.

Table 2. Testing correlations of personal attitudes and employability perception

\begin{tabular}{|c|c|c|c|}
\hline \multicolumn{4}{|c|}{ Correlations } \\
\hline \multirow{3}{*}{ E } & Pearson Correlation & 1 & $.756^{* *}$ \\
\cline { 2 - 4 } & Sig. (1-tailed) & & .000 \\
\cline { 2 - 4 } & $\mathrm{N}$ & 349 & 349 \\
\hline \multirow{3}{*}{ PA } & Pearson Correlation & $.756^{* *}$ & 1 \\
\cline { 2 - 4 } & Sig. (1-tailed) & .000 & \\
\cline { 2 - 4 } & $\mathrm{N}$ & 349 & 349 \\
\hline
\end{tabular}

**. Correlation is significant at the 0.01 level (1-tailed).

The above table shows that the correlation coefficient (Pearson's correlation coefficient) between students' personal attitudes and perception of employability (a hypothetically modeled predictor variable and the criterion variable) is .756, which makes the interconnection between these two variables sufficiently strong and indicates that it is necessary, i.e. it makes sense, to test the regression relation of these variables in accordance with previously defined logical patterns and hypotheses to assess if they hold true. The values in row two indicate that the correlation between the two above variables is significant. Following the basic logic, the probability shown here is one-sided/one-directional, but since the score in this case is so very, low, on the order of 0.000 , even if it were doubled, the value thus obtained would still be very low, so its significance may not be questioned even in such a case. Therefore, the linear correlation coefficient in this case is statistically significant and positive. Naturally, $\mathrm{N}$ reminds about the sample size. If the Scatter Plot Diagram has formed for the two above variables that has been taken in consideration it could be seen that the distribution of points reveals the positive relationships between respondents' personal attitudes and their perceived employability, which is shaped as a linear correlation. The Scatter Plot Diagram leads to the conclusion that a positive linear relationship between these two variables is indicated, which will be modeled, examined and tested below to prove stated hypotheses. Next, it is examined whether there was an interconnection between social norms and the perception of employability of the participants in the CEO Conference.

Table 3. Testing correlations of social norms and employability perception

\begin{tabular}{|c|c|c|c|}
\hline \multicolumn{4}{|c|}{ Correlations } \\
\hline \multirow{3}{*}{ E } & Pearson Correlation & 1 & $.758^{* *}$ \\
\cline { 2 - 4 } & Sig. (1-tailed) & & .000 \\
\cline { 2 - 4 } & N & 349 & 349 \\
\hline \multirow{3}{*}{ SN } & Pearson Correlation & $.758^{* *}$ & 1 \\
\cline { 2 - 4 } & Sig. (1-tailed) & .000 & \\
\cline { 2 - 4 } & N & 349 & 349 \\
\hline
\end{tabular}

**. Correlation is significant at the 0.01 level (1-tailed).
The table above shows that the correlation coefficient (Pearson's correlation coefficient) between the observed variables of social norms and students' employability perception) between the assumed predictor variable and the criterion variable of the chosen theoretical research model is .758 , which makes the interconnection of these two variables (notion of social norms as an assumed predictor variable and perceived employability as the criterion variable) very strong and signals that it is necessary, i.e. that makes sense, to test the regressivity of these variables in accordance with previously defined logical patterns. The values in row two indicate that the correlation between these two variables in significant, while other elements may be interpreted as in the case of the relationship with the first assumed predictor variable. In this case as well, the dispersion diagram yield a visual outline that signals a positive linear correlation between these two variables, while the table below shows the relationship between participants' innovativeness and their perception of employability.

Table 4. Testing correlations of innovativeness and employability perception

\begin{tabular}{|c|c|c|c|}
\hline \multicolumn{4}{|c|}{ Correlations } \\
\hline \multirow{3}{*}{ E } & Pearson Correlation & 1 & $.799^{* *}$ \\
\cline { 2 - 4 } & Sig. (1-tailed) & & .000 \\
\cline { 2 - 4 } & $\mathrm{N}$ & 349 & 349 \\
\hline \multirow{3}{*}{ I } & Pearson Correlation & $.799^{* *}$ & 1 \\
\cline { 2 - 4 } & Sig. (1-tailed) & .000 & \\
\cline { 2 - 4 } & $\mathrm{N}$ & 349 & 349 \\
\hline
\end{tabular}

**. Correlation is significant at the 0.01 level (1-tailed).

The above table shows that the correlation coefficient (Pearson's correlation coefficient between a hypothetically assumed predictor variable and the criterion variable is .799 , which makes the interconnection between these two variables (innovativeness as the assumed predictor variable and employability as the criterion variable) very strong and indicates that it is necessary, i.e. it makes sense, to test the regressivity of these variables in accordance with previously defined logical patterns, while other element and the dispersion diagram are very similar as in the two preceding cases. Previously examined correlations created the foundations for subsequent modelling of regression relationships that would result in a better understanding of causal relationships between the defined variables.

\section{Modelling of Regressions between Variables}

The objective of a single regression analysis is to explain variability (individual differences) in the criterion variable by the variability (individual differences) in the predictor variable. If multiple predictor variables are incorporated 
into the model, it becomes a multiple linear regression. The second objective of linear regression is to formulate a model to predict criterion variable values for a given entity in the population on the basis of that entity's results for the predictor variable. In other words, if we know the given value of the entity for the predictor variable, and it cannot be known what its value is for the criterion variable, its value may be estimated on the basis of the model.

In this study, the variable Personal attitudes is taken as predictor variable in the first linear regression, and perceived Employability as the criterion variable. If this were a typical experiment, the predictor variable would be termed "independent variable", while the criterion variable would be termed "dependent variable", but in social science research ono often may not start from the assumption of a strictly profiled experiment, but instead relationships linked with attitudes and competences are studied, so in terminological terms this is a relationship between the predictor and criterion variables.

The above table (Table no. 5) presents all variables that were subject to analysis and that were entered into the assumed model of linear regression, which would be analyzed and tested on the basis of other statistical data. In this case, the following two variables were presented: respondents' Personal attitudes (PA) and their perceived Employability (E).

Table 5. Testing regression of personal attitudes to employability perception

\begin{tabular}{|c|c|c|c|c|}
\hline \multicolumn{5}{|c|}{ Model Summary $^{\mathbf{b}}$} \\
\hline Model & $\mathrm{R}$ & R Square & $\begin{array}{c}\text { Adjusted R } \\
\text { Square }\end{array}$ & $\begin{array}{c}\text { Std. Error of the } \\
\text { Estimate }\end{array}$ \\
\hline 1 &, $756^{\mathrm{a}}$ & .571 & .570 & .60417 \\
\hline
\end{tabular}

a. Predictors: (Constant), PA

b. Dependent Variable: E

The above table (Table no. 5) shows the absolute value of the correlation coefficient, which was already stated as $\mathrm{R}=.756$, while $\mathrm{R}$ Square $=.571$ represents the determination coefficient and Adjusted R Square stands for adjusted determination coefficient. The latter constitutes a more realistic indicator (less biased assessment) with the value of .571 , which does not constitute a significant deviation from the first indicator, although logically it should tend to be a bit lower, regardless that $\mathrm{N}$ is greater than 200 , and then no major deviation is expected, since the quotient in the formula for calculation of the adjusted determination coefficient tends to be equal to one.

On the basis of the determination coefficient, we see that around $57 \%$ of individual differences, i.e. of variability of the criterion variable "perceived Employability", determined by means of the predictor variable Personal attitudes, which indicates a rather solid and strong causal relationship. In other words, $57 \%$ of students' Employability perception was determined by their personal attitudes in the sense of their way of thinking, generation of ideas and the manner of study, development of partnership networks etc. The standard error, irrelevant for this segment, in the case when the second objective of regression would be used, which is the prediction of the movement of the criterion variable, that we do not know, in dependence of the criterion variable, which we know, the estimation error would be around .6, which is comparatively good for this type of research, i.e. sufficient basis to make relevant estimates, i.e. predictions. As shown, the standard estimation error is smaller than the standard error for the criterion variables, which is around .9, and thereby also smaller than one. In this case, the standard deviation of the criterion variable reveal the percentage error of estimation if we did not know any other value of the predictor variable except its arithmetic mean, which means that we would err by .9 units in the units of measurement of students' perceptions in the context of the level of their employability, and if the arithmetic mean of the predictor variable were known, then the error would be .6 units of the units for measurement of students' personal attitudes. Finally, since the standard prediction/estimation error is .6, this model can, to an extent, serve as a moderately solid basis for estimation of the criterion variable. To completely present the process of analysis and conclusion, the variance analysis is presented below.

Table 6. Testing the first auxiliary hypothesis

\begin{tabular}{|c|c|c|c|c|c|c|}
\hline \multicolumn{7}{|c|}{ ANOVA $^{\mathrm{a}}$} \\
\hline \multicolumn{2}{|c|}{ Model } & $\begin{array}{c}\text { Sum of } \\
\text { Squares }\end{array}$ & df & $\begin{array}{c}\text { Mean } \\
\text { Square }\end{array}$ & F & Sig. \\
\hline \multirow{3}{*}{1} & Regression & 168.874 & 1 & 168.874 & 462,635 & $.000^{\mathrm{b}}$ \\
\cline { 2 - 8 } 1 & Residual & 126.664 & 347 & .365 & & \\
\cline { 2 - 8 } & Total & 295.538 & 348 & & & \\
\hline
\end{tabular}

a. Dependent Variable: E

b. Predictors: (Constant), PA

For a regression model to be considered relevant for application to the population from which it was derived at random, the hypothesis, i.e. the null hypothesis should be tested by the F test. All data required to apply this test to the null hypothesis, which starts with the assumption that the determination coefficient between the predictor and criterion variables in the population is equal to zero are found in the ANOVA statistics table, i.e. in the variance analysis table. It contains the overall sum of squares of the criterion variable, sum of regression squares, and the sum of errors squared, i.e. of residuals. Above hypothesis may be formulated as follows: $H_{0}: \rho^{2}=0$, with $\rho^{2}$ representing the determination coefficient, which is not equal to zero in this study, indicating that the null hypothesis should be discarded, and the research hypothesis should be accepted, as phrased in the form of the first auxiliary hypothesis. 
Table 7. Predicting PA-E regression model

\begin{tabular}{|c|c|c|c|c|c|c|c|c|}
\hline \multicolumn{2}{|c|}{ Coefficients $^{\mathbf{2}}$} \\
\hline \multirow{2}{*}{ Model } & \multicolumn{2}{|c|}{ Unstandardized Coefficients } & $\begin{array}{c}\text { Standardized } \\
\text { Coefficients }\end{array}$ & \multirow{2}{*}{ tons } & \multirow{2}{*}{ Sig. } & \multicolumn{2}{|c|}{$95.0 \%$ Confidence Interval for B } \\
\cline { 3 - 10 } & B & Std. Error & Beta & & & Lower Bound & Upper Bound \\
\hline \multirow{2}{*}{1} & (Constant) & .748 & .144 & & 5.181 & .000 & .464 & 1,032 \\
\cline { 2 - 10 } & PA & .823 & .038 & .756 & 21.509 & .000 & .747 & .898 \\
\hline
\end{tabular}

a. Dependent Variable: E

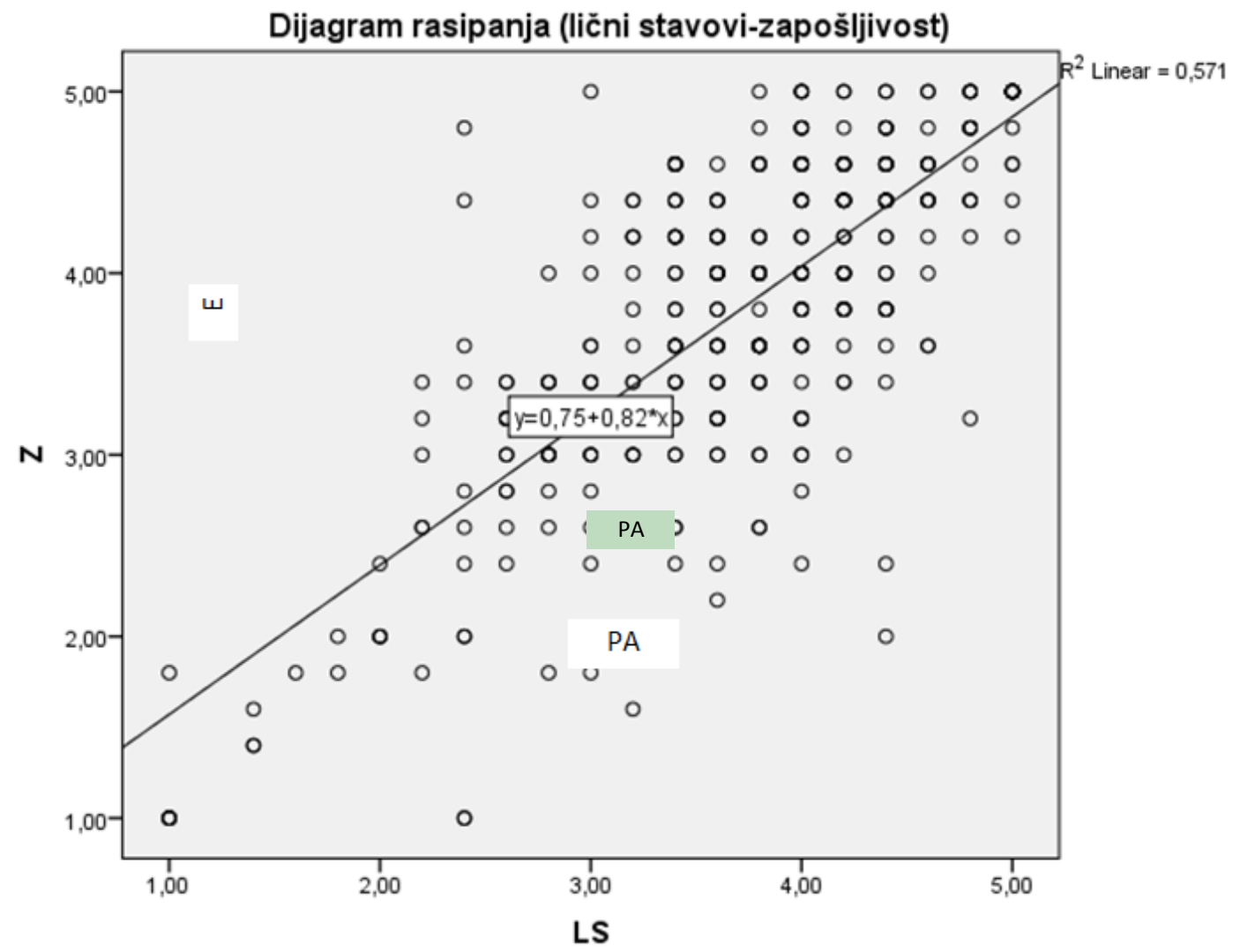

Figure 1. Scatter Plot Diagram for the Personal Attitudes - perceived Employability relationship, with formulas

As sig $=.000$, i.e. the score assumes the value smaller than .05 , the $\mathrm{F}$ test is considered significant (if the null hypothesis is correct, the F statistics exhibits Snidikor's distribution, with $\mathrm{n}-2$ degrees of freedom), so the null hypothesis may be discarded and a claim can be made that the regression model may be used to explain changes in the population. There is a regression of the predictor variable to the criterion one, indicating that the first auxiliary research hypothesis, which assumes the interconnection of these variables, may be accepted. Additional statistical indicators are examined below to predict a regression model, i.e. a regression equation for this study.

The above table reveals that the $T$ probability is identical to the $\mathrm{F}$ statistics probability, and that the latter is significant, which is necessary for this kind of analysis of single linear connections. On the basis of the above, it is possible to construct the next regression model, so it would be E (perceived Employability) $=.748+.823$ PA (Personal attitudes). If the model is sufficiently precise, then knowing the values of the predictor variable it might be possible to estimate the value of the criterion variable. It is evident that the value of the standardized regression coefficient (.756) in the regression model in this case is equal to the value of the linear correlation, and this is essential in case that the model functions with a single predictor variable. The significance of the determination coefficient may be determined also from the confidence interval, which is $95 \%$, and that is $95 \%$ certainty that this interval included the regression bias, i.e. that the parameter (regression bias) of the population belongs to this interval, and that it is not zero, as shown in the preceding table.

Figure 1 already allows to detect more concrete relationships between the predictor variable Personal attitudes (PA) and the criterion variable perceived Employability (E), so that it is evident that the linear regression model is identical, although the system 
performed some rounding to the second decimal, and certainly, and certainly with an identical value of the determination coefficient of .571 . The residuals statistics is presented below.

Table 8. PA-E residuals statistics

\begin{tabular}{|c|c|c|c|c|c|}
\hline \multicolumn{7}{|c|}{ Residuals Statistics $^{\mathbf{a}}$} \\
\hline & Minimum & Maximum & Mean & $\begin{array}{c}\text { Std. } \\
\text { Deviation }\end{array}$ & $\mathrm{N}$ \\
\hline Predicted Value & 1.5706 & 4.8609 & 3.7748 & .69661 & 349 \\
\hline Residual & -2.36732 & 2.07782 & .00000 & .60331 & 349 \\
\hline $\begin{array}{c}\text { Std. Predicted } \\
\text { Value }\end{array}$ & -3.164 & 1.559 & .000 & 1.000 & 349 \\
\hline Std. Residual & -3.918 & 3.439 & .000 & .999 & 349 \\
\hline
\end{tabular}

a. Dependent Variable: E

The above table (Table no. 8) shows maximum and minimum residual values, their arithmetic mean and standard deviations, and, naturally, the number of units in the sample. The arithmetic mean of the residuals equals zero, which is necessary in this case, while the arithmetic mean of prediction values has the identical value as the arithmetic mean obtained from empirical data (3.7748).

Below we analyze the regression model for the SN (Social norms) predictor variable to the $\mathrm{E}$ (perceived Employability) criterion variable. The data in the following tables will allow us to examine whether it is justified to use the model of the single linear regression between the second predictor variable and criterion variable.

Table 9. Testing regression of social norms to employability perception

\begin{tabular}{|c|c|c|c|c|}
\hline \multicolumn{5}{|c|}{ Model Summary $^{\mathbf{b}}$} \\
\hline Model & $\mathrm{R}$ & R Square & $\begin{array}{c}\text { Adjusted R } \\
\text { Square }\end{array}$ & $\begin{array}{c}\text { Std. Error of the } \\
\text { Estimate }\end{array}$ \\
\hline 1 & $.758^{\mathrm{a}}$ & .575 & .574 & .60154 \\
\hline
\end{tabular}

a. Predictors: (Constant), SN

b. Dependent Variable: E

The above table (Table no. 9) shows the absolute value of the correlation coefficient, which was already listed as $\mathrm{R}=.758$, while $\mathrm{R}$ Square $=.575$ represents the coefficient of determination and Adjusted R Square stands for adjusted coefficient of determination. The latter constitutes a more realistic indicator (less biased assessment) with the value of .574 , which does not constitute a significant deviation from these two indicators, although logically it tends to be a bit lower, regardless that $\mathrm{N}$ is greater than 200 , and then no major deviation is expected, since the quotient in the formula for calculation of the adjusted determination coefficient tends to be equal to one. This is evident if the calculation elements are entered into the formula and the calculation is performed as in the previous example. To completely present the process of analysis and conclusion, the variance analysis is presented below.

Table 10. Testing the second auxiliary hypothesis

\begin{tabular}{|c|c|c|c|c|c|c|}
\hline \multicolumn{7}{|c|}{ ANOVA $^{\mathbf{a}}$} \\
\hline \multicolumn{2}{|c|}{ Model } & $\begin{array}{c}\text { Sum of } \\
\text { Squares }\end{array}$ & df & $\begin{array}{c}\text { Mean } \\
\text { Square }\end{array}$ & F & Sig. \\
\hline \multirow{4}{*}{1} & Regression & 169.978 & 1 & 169.978 & 469.752 & $.000^{\mathrm{b}}$ \\
\cline { 2 - 7 } & Residual & 125.560 & 347 & .362 & & \\
\cline { 2 - 7 } & Total & 295.538 & 348 & & & \\
\hline
\end{tabular}

a. Dependent Variable: E

b. Predictors: (Constant), SN

For a regression model to be considered relevant for application to the population from which it was derived at random, the hypothesis, i.e the null hypothesis should be tested by the $\mathrm{F}$ test. All data required to apply this test to the null hypothesis, which starts with the assumption that the determination coefficient between the predictor and criterion variables in the population is equal to zero, are found in the ANOVA statistics table, i.e. in the variance analysis table. It contains the overall sum of squares of the criterion variable, sum of regression squares, and the sum of errors squared, i.e. of residuals. The above hypothesis may be formulated as follows: $H_{0}: \rho^{2}=0$, with $\rho^{2}$ representing the determination coefficient, which is not equal to zero in this study, indicating that the null hypothesis should be discarded, and the research hypothesis, that assumes influence of students' social norms (SN), should be accepted as the predictor variable and criterion variable of students' perceived Employability (E).

As sig $=.000$, i.e. the score assumes the value smaller than .05 , the $\mathrm{F}$ test is considered significant (if the null hypothesis is correct, the F statistics exhibits Snidikor's distribution, with $n-2$ degrees of freedom), so the null hypothesis may be discarded and a claim can be made that the regression model may be used to explain changes in the population. There is a regression of the predictor variable to the criterion one, indicating that the second auxiliary research hypothesis, which assumes the interconnection of these variables, may be accepted. Additional statistical indicators are examined below to predict a regression model, i.e. a regression equation for this study.

Table 11. Predicting SN-E regression model

\begin{tabular}{|c|c|c|c|c|c|c|c|c|}
\hline \multicolumn{9}{|c|}{ Coefficientsa } \\
\hline \multirow{2}{*}{\multicolumn{2}{|c|}{ Model }} & \multicolumn{2}{|c|}{$\begin{array}{c}\text { Unstandardized } \\
\text { Coefficients }\end{array}$} & \multirow{2}{*}{$\begin{array}{c}\text { Standardized Coefficients } \\
\text { Beta }\end{array}$} & \multirow{2}{*}{ tons } & \multirow{2}{*}{ Sig. } & \multicolumn{2}{|c|}{$95.0 \%$ Confidence Interval for B } \\
\hline & & B & Std. Error & & & & Lower Bound & Upper Bound \\
\hline \multirow{2}{*}{1} & (Constant) & .770 & .142 & & 5.407 & .000 & .490 & 1.050 \\
\hline & SN & .801 & .037 & .758 & 21.674 & .000 & .728 & .874 \\
\hline
\end{tabular}

a. Dependent Variable: E 
The above table reveals that the $\mathrm{T}$ probability is identical to the F statistics probability, which is necessary for this kind of single linear connections. On the basis of the above, it is possible to construct the next regression model, so it would be $\mathrm{E}$ (perceived Employability) $=.770+.801 \mathrm{SN}$ (Social norms). If the model is sufficiently precise, then knowing the values of the predictor variable may make it possible to estimate the value of the criterion variable. It is evident that the value of the standardized regression coefficient (.758) in the regression model in this case is equal to the value of the linear correlation, and this is necessary in case that the model treats a single predictor variable. The significance of the determination coefficient may be determined also from the confidence interval, which is $95 \%$, and that is $95 \%$ certainty that this interval included the regression bias, i.e. that the parameter (regression bias) of the population belongs to this interval, and that it is not equal to zero, as shown in the preceding table.

Table 12. SN-E residuals statistics

\begin{tabular}{|c|c|c|c|c|c|}
\hline \multicolumn{7}{|c|}{ Residuals Statistics $^{\text {a }}$} \\
\hline & Minimum & Maximum & Mean & $\begin{array}{c}\text { Std. } \\
\text { Deviation }\end{array}$ & $\mathrm{N}$ \\
\hline Predicted Value & 1.5706 & 4.7745 & 3.7748 & .69889 & 349 \\
\hline Residual & -1.85219 & 1.98762 & .00000 & .60067 & 349 \\
\hline $\begin{array}{c}\text { Std. Predicted } \\
\text { Value }\end{array}$ & -3.154 & 1.430 & .000 & 1.000 & 349 \\
\hline Std. Residual & -3.079 & 3.304 & .000 & .999 & 349 \\
\hline
\end{tabular}

a. Dependent Variable: E

The above table shows maximum and minimum residual values, their arithmetic means and standard deviations, and, of course, the number of units in the sample. The arithmetic mean of the residuals equals zero, which is necessary in this case, while the arithmetic mean of prediction values has the identical value as the arithmetic mean obtained from empirical data (3.7748).

The regression model of the predictor variable I (Innovativeness) to the criterion variable $\mathrm{E}$ (perceived Employability) is analyzed below. The data from the following tables will be used to examine whether it is justified to use the model of the single linear regression between the third predictor variable and the criterion variable, which is assumed in the third auxiliary hypothesis. The data from the following tables will be used to examine whether it is justified to use the model of the single linear regression between the second predictor variable and the criterion variable.

Table 13. Testing regression of innovativeness to employability perception

\begin{tabular}{|c|c|c|c|c|}
\hline \multicolumn{5}{|c|}{ Model Summary $^{\mathbf{b}}$} \\
\hline Model & R & R Square & $\begin{array}{c}\text { Adjusted R } \\
\text { Square }\end{array}$ & $\begin{array}{c}\text { Std. Error of the } \\
\text { Estimate }\end{array}$ \\
\hline 1 &, $799^{\mathrm{a}}$ & .638 & .637 & .55548 \\
\hline
\end{tabular}

a. Predictors: (Constant), I

b. Dependent Variable: E

The above table shows the absolute value of the correlation coefficient, which was already listed as $\mathrm{R}=.799$, while $\mathrm{R}$ Square $=.638$ represents the determination coefficient and Adjusted R Square stands for adjusted determination coefficient. The latter constitutes a more realistic indicator (less biased assessment) with the value of .637 , which does not constitute a significant deviation from these two indicators, although logically it tends to be a bit lower, regardless that $\mathrm{N}$ is greater than 200 , and then no major deviation is expected, since the quotient in the formula for calculation of the adjusted determination coefficient tends to be equal to one. This is evident if the calculation elements are entered into the formula and the calculation is performed as in the previous example. To completely present the process of analysis and conclusion, the variance analysis is presented below.

Table 14. Testing the third auxiliary hypothesis

\begin{tabular}{|c|c|c|c|c|c|c|}
\hline \multicolumn{7}{|c|}{ ANOVA $^{\text {a }}$} \\
\hline \multicolumn{2}{|c|}{ Model } & $\begin{array}{c}\text { Sum of } \\
\text { Squares }\end{array}$ & df & $\begin{array}{c}\text { Mean } \\
\text { Square }\end{array}$ & F & Sig. \\
\hline \multirow{3}{*}{1} & Regression & 188.470 & 1 & 188.470 & 610.814 & $.000^{\mathrm{b}}$ \\
\cline { 2 - 8 } & Residual & 107.069 & 347 & .309 & & \\
\cline { 2 - 8 } & Total & 295.538 & 348 & & & \\
\hline
\end{tabular}

a. Dependent Variable: E

b. Predictors: (Constant), I

For a regression model to be considered relevant for application to the population from which it was derived at random, the hypothesis, i.e. the null hypothesis should be tested by the F test. All data required to apply this test to the null hypothesis, which starts with the assumption that the determination coefficient between the predictor and criterion variables in the population is equal to zero, are found in the ANOVA statistics table, i.e. in the variance analysis table. It contains the overall sum of squares of the criterion variable, sum of regression squares, and the sum of errors squared, i.e. of residuals. The above hypothesis may be formulated as follows: $H_{0}: \rho^{2}=0$, with $\rho^{2}$ representing the determination coefficient, which is not equal to zero in this study, indicating that the null hypothesis should be discarded, and the research hypothesis, that assumes influence of students' innovativeness (I), should be accepted as the predictor variable and criterion variable of students' perceived Employability (E).

As sig $=.000$, i.e. the score assumes the value smaller than .05 , the $\mathrm{F}$ test is considered significant (if the null hypothesis is correct, the F statistics exhibits Snidikor's distribution, with n-2 degrees of freedom), so the null hypothesis may be discarded and a claim can be made that the regression model may be used to explain changes in the population. There is a regression of the predictor variable to the criterion one, indicating that the third auxiliary research hypothesis, which assumes the interconnection of these variables, may be accepted. Additional statistical indicators are examined below to predict a regression model, i.e. a regression equation for this study. 
Table 15. Predicting I-E regression model

\begin{tabular}{|c|c|c|c|c|c|c|c|c|}
\hline \multicolumn{9}{|c|}{ Coefficients $\mathrm{s}^{\mathrm{a}}$} \\
\hline \multirow{2}{*}{\multicolumn{2}{|c|}{ Model }} & \multicolumn{2}{|c|}{ Unstandardized Coefficients } & \multirow{2}{*}{$\begin{array}{c}\begin{array}{c}\text { Standardized } \\
\text { Coefficients }\end{array} \\
\text { Beta }\end{array}$} & \multirow{2}{*}{ tons } & \multirow{2}{*}{ Sig. } & \multicolumn{2}{|c|}{$\begin{array}{c}95.0 \% \text { Confidence Interva } \\
\text { for B }\end{array}$} \\
\hline & & B & Std. Error & & & & $\begin{array}{l}\text { Lower } \\
\text { Bound }\end{array}$ & Upper Bound \\
\hline \multirow{2}{*}{1} & (Constant) & .527 & .135 & & 3.913 & .000 & .262 & .792 \\
\hline & I & .819 & .033 & .799 & 24.715 & .000 & .754 & .884 \\
\hline
\end{tabular}

a. Dependent Variable: E

The above table reveals that the $\mathrm{T}$ probability is identical to the $\mathrm{F}$ statistics probability, which is necessary for this kind of single linear connections. On the basis of the above, it is possible to construct the next regression model, so it would be $\mathrm{E}$ (perceived Employability) $=.527+.819 \mathrm{I}$ (Innovativeness). If the model is sufficiently precise, then knowing the values of the predictor variable may make it possible to estimate the value of the criterion variable. It is evident that the value of the standardized regression coefficient (.799) in the regression model in this case is equal to the value of the linear correlation, and this is necessary in case that the model treats a single predictor variable. The significance of the determination coefficient may be determined also from the confidence interval, which is $95 \%$, and that is $95 \%$ certainty that this interval included the regression bias, i.e. that the parameter (regression bias) of the population belongs to this interval, and that it is not zero, as shown in the above table.

Table 16. I-E residuals statistics

\begin{tabular}{|c|c|c|c|c|c|}
\hline \multicolumn{7}{|c|}{ Residuals Statistics $^{\mathbf{a}}$} \\
\hline & Minimum & Maximum & Mean & $\begin{array}{c}\text { Std. } \\
\text { Deviation }\end{array}$ & $\mathrm{N}$ \\
\hline Predicted Value & 1.3465 & 4.6236 & 3.7748 & .73592 & 349 \\
\hline Residual & -2.05979 & 1.70649 & .00000 & .55468 & 349 \\
\hline $\begin{array}{c}\text { Std. Predicted } \\
\text { Value }\end{array}$ & -3.300 & 1.153 & .000 & 1.000 & 349 \\
\hline Std. Residual & -3.708 & 3.072 & .000 & .999 & 349 \\
\hline
\end{tabular}

a. Dependent Variable: E

The above table shows maximum and minimum residual values, their arithmetic means and standard deviations, and, of course, the number of units in the sample. The arithmetic mean of the residuals equals zero, which is necessary in this case, while the arithmetic mean of prediction values has the identical value as the arithmetic mean obtained from empirical data (3.7748).

Below we analyze the multiple regression model for the PA (Personal attitudes), SN (Social norms) and I (Innovativeness) predictor variables to the $\mathrm{E}$ (perceived employability) criterion variable. The data from the following tables will be used to examine whether it is justified to use the multiple linear regression model between the three predictor variable and the criterion variable.
Table 17. Multiple regression of predictor variables to criterion variable

\begin{tabular}{|c|c|c|c|c|}
\hline \multicolumn{5}{|c|}{ Model Summary $^{\mathbf{b}}$} \\
\hline Model & $\mathrm{R}$ & R Square & $\begin{array}{c}\text { Adjusted R } \\
\text { Square }\end{array}$ & $\begin{array}{c}\text { Std. Error of the } \\
\text { Estimate }\end{array}$ \\
\hline 1 & $.842^{\mathrm{a}}$ & .710 & .707 & .49877 \\
\hline
\end{tabular}

a. Predictors: (Constant), I, SN, PA

b. Dependent Variable: E

The above table shows the value of the multiple regression $(\mathrm{R}=.842)$, as well as the determination, i.e. multiple regression, coefficient (R Square $=.710$ ), and the adjusted multiple regression coefficient, which is somewhat lower, and its value is 0.707 . It constitutes a less biased indicator, which decreases as the number of predictor variables increases, and the number of units in the sample decreases. The value of the model's estimated standard error is low enough, nearly half the standard error of the criterion variable, thus the model may serve to provide sound estimate, i.e prediction of the criterion variable on the basis of the linear combination of predictor variables in the model. The data above show that the change in the criterion variable may be explained by changes in predictor variables, i.e. in their linear combination. To completely present the process of analysis and conclusion, the variance analysis is presented below.

Table 18. Testing of the main research hypothesis

\begin{tabular}{|c|c|c|c|c|c|c|}
\hline \multicolumn{7}{|c|}{ ANOVA $^{\mathbf{a}}$} \\
\hline \multicolumn{2}{|c|}{ Model } & $\begin{array}{c}\text { Sum of } \\
\text { Squares }\end{array}$ & df & $\begin{array}{c}\text { Mean } \\
\text { Square }\end{array}$ & F & Sig. \\
\hline \multirow{3}{*}{1} & Regression & 209.712 & 3 & 69.904 & 280.995 & $.000^{\mathrm{b}}$ \\
\cline { 2 - 7 } & Residual & 85.827 & 345 & .249 & & \\
\cline { 2 - 7 } & Total & 295.538 & 348 & & & \\
\hline
\end{tabular}

a. Dependent Variable: E

b. Predictors: (Constant), I, SN, PA

The above ANOVA table presents the analysis that offers information about the significance of the F statistics, indicating that the null hypothesis, which assumes absence of regression of predictor variables to the criterion variable, may be discarded. This effectively indicates that the main research hypothesis set for this study may be accepted. Additional statistical indicators are examined below to predict the multiple regression model, i.e. the combination of regression equations for this study. 
Table 19. Prediction of the (PA, SN, I)-E regression model

\begin{tabular}{|c|c|c|c|c|c|c|c|c|c|c|}
\hline \multicolumn{11}{|c|}{ Coefficients $^{\mathrm{a}}$} \\
\hline & \multirow{2}{*}{ Model } & \multicolumn{2}{|c|}{$\begin{array}{l}\text { Unstandardized } \\
\text { Coefficients }\end{array}$} & \multirow{2}{*}{$\begin{array}{c}\text { Standardized } \\
\text { Coefficients } \\
\text { Beta }\end{array}$} & \multirow{2}{*}{ tons } & \multirow{2}{*}{ Sig. } & \multicolumn{2}{|c|}{$\begin{array}{l}95.0 \% \text { Confidence Interval } \\
\text { for B }\end{array}$} & \multicolumn{2}{|c|}{ Collinearity Statistics } \\
\hline & & B & Std. Error & & & & Lower Bound & Upper Bound & Tolerance & VIF \\
\hline \multirow{4}{*}{1} & (Constant) & .099 & .130 & & .760 & .448 & -.156 & .353 & & \\
\hline & PA & .234 & .056 & .215 & 4.194 & .000 & .124 & .344 & .320 & 3.125 \\
\hline & SN & .309 & .050 & .293 & 6.210 & .000 & .211 & .407 & .379 & 2.640 \\
\hline & I & .418 & .054 & .407 & 7.775 & .000 & .312 & .523 & .307 & 3.255 \\
\hline
\end{tabular}

a. Dependent Variable: E

In this case, the $\mathrm{T}$ test indicates that all partial regression coefficients are above .10 and that they are significant. Even if the partial regression coefficients are not significant, and if they are high, it is not always wise to automatically exclude a predictor from the model without additional analysis. These conditions are met in this study and all predictors are taken into consideration as relevant. Besides non-standard partial determination coefficients, standardized partial determination coefficients are useful for analysis and interpretation, as they indicate what their values are if other predictors are held constant at their means, for instance when we change predictor I (Innovativeness) by one unit, in this case by one standard deviation, the criterion variable $\mathrm{E}$ (perceived Employability), i.e. its standard deviation will change by .407 , with other predictors held constant. In other words, when the students' innovativeness increases by one standard deviation, their employability increases by .407 standard deviation, making evident the positive impact of innovativeness as a students' trait to their perception of employability in the labor market, and therefore, logically, also to their practical status in the labor market. The partial regression coefficients are treated here as this is a multiple regression, where a partial regression coefficient for a given predictor variable indicates a unique specific influence of the given predictor variable on the change in the criterion variable, when other predictors are held constant, i.e. explains its influence in the context of the combination of other predictors in the model. It is possible that a predictor variable has a significant correlation with the criterion variable without having a significant partial determination coefficient with it, which is not the case here. The partial determination coefficient does not depend solely on the features of the predictor variable itself, but it is also affected by the changes in other predictor variables in the model. In this case, testing of the constant is not relevant for the study, and it is not necessary to devise a situation when the significance of the constant is equal to zero, since the partial regression coefficients of individual predictors to the criterion variable are both high enough and significant. The key hypotheses that should be tested by the $\mathrm{F}$ and $\mathrm{T}$ tests, when all predictor variables are simultaneously incorporated in the model is, in effect the hypothesis about the multiple determination coefficient (null hypothesis assumes that the multiple determination coefficient is equal to zero, i.e. that predictor variables have no influence on the criterion variable, while the research hypothesis (the main research hypothesis - hypothesis 1 in this case) states the opposite:

$$
\begin{aligned}
& H_{0}: \mathrm{P}^{2}=0 \\
& H_{1}: \mathrm{P}^{2} \neq 0
\end{aligned}
$$

so the regression parameters hypothesis, i.e. the hypothesis on partial determination coefficients for individual predictor variables to the criterion variables, in relation to the population, is expressed as follows:

$$
H_{0(j)}: \beta_{j}=0, j=1,2, \ldots, m
$$

Naturally, in this case the research hypothesis also makes the opposite claim, i.e. starts with the assumption that partial determination coefficients are not equal to zero, i.e. that there is a connection between predictor variables and the criterion variable. As evident from the F statistics, which is positive and significant, the null hypothesis is discarded because the multiple regression coefficient is positive and significant. The $\mathrm{T}$ statistics shows a positive and significant score, while partial determination coefficients are also positive, which mean that the null hypothesis on regression parameters being equal to zero is discarded, and research hypotheses about the existence of a positive and significant relationship between predictor variables and the criterion variable is accepted. Mathematically, in this case the multiple regression model may be expressed as follows: $\mathrm{E}=.099+.234 \mathrm{PA}+.309 \mathrm{SN}+.418 \mathrm{I}$. In this study it is also necessary to analyze the Collinearity Statistics in the Coefficients $^{\mathrm{a}}$ table, where the tolerance option may be observed and where it is possible to examine the redundancy of predictor variables and tolerance with values considerably over .10, When values are below .10, it means that over $90 \%$ of the variability of the given predictor variable is common with other predictor variables, making the given variable superfluous, and then it should be excluded from the model, since it may cause problems in the multiple regression model. In this study it is not the case, so even after this test all predictor variables may be taken a relevant. The question of redundancy of any of the predictor variables does not arise here, as no predictor has a VIF - Variance Inflation Factor (it constitutes a reciprocal value to the tolerance value) greater than ten. If that were 
the case, this would have to be taken into account and the predictor variables with values greater than ten would have to be eliminated from the model, as it would mean that the bulk of the variability of a particular predictor variable $\mathrm{i}$ defined by two others, and it should be eliminated, but it is not the case in this study, so the model withstood this test a well.

The specific multiple regression model leads to the conclusion that changes to three predictor variables account for over $70 \%(.842, .710$ and .707$)$, as shown in the Model Summary table 17., of the variance of the criterion variable, which effectively proves the main research hypothesis that the contents and activities of the CEO Conference of the Sarajevo University-School of Economics in Sarajevo, expressed in the form of development of students' personal attitudes, social norms and innovativeness, have positive influence on their employability, which was the purport of this study. Further analysis might examine which of the predictor variables has the largest individual influence on the criterion variable through incorporation into the analysis of some additional statistical indicators shown in the following table. For clarity purposes, predictors may be introduced one by one, gradually, step by step, in order to identify the contribution of each new predictor to the change (variability), i.e. for explanation or prediction of variability in the criterion variable. In this fashion, it is possible to obtain the squares of semi-partial correlations of the latest predictor to be introduced and these squares represent a solid measurement of the validity of introduction of the new predictor in the model, which was proven justified in the framework of this study.

When reading Table no. 20 (Model Summary), R Square Change, i.e. the change of the determination coefficient, should be taken as an important indicator, where it is evident that its change in the second model, where an additional predictor variable is introduced, relative to the first one, where only the first predictor variable was taken into account, is equal to .087 (R Square change $(2)=.087$ ), which indicates that the additional predictor, after the introduction into the model, has an additional influence on the changes to the criterion variable of around $9 \%(.087)$, i.e. around $9 \%$ additional explanation of changes in the criterion variable, while that amount of contribution to changes in the criterion variable by introduction of the third predictor variable is around 5\% (.051). Each contribution of $5 \%$ and above is statistically significant and should be taken into account, i.e. each predictor that generates it should be incorporated into the model as significant, while in some cases of more detailed logic-based research and of practical significance of predictors, it may be incorporated into the model even if its additional influence is non-significant and lower than $5 \%$, but higher than $1 \%$, as a predictor with additional influence lower than $1 \%$ should not be taken into account regardless of statistical significance. In this case, both additional predictors meet both practical and statistical requirements, so in this study both have been incorporated into the multiple regression model. It is evident that all above indicators connected with the changes of the determination coefficient through introduction of additional predictors into the model are statistically significant (Sig. F Change $=.000$ ), which indicates that there is statistical justification for incorporation of the above predictors into the integral multiple linear regression model. With the addition of new predictors to the model, its complexity increases, while purpose of the analysis is to make the model as simple as possible. At the same time it should explain the as much as possible of the phenomenon, attitude, or criterion variable by choosing the predictors with the greatest contribution, i.e. greatest strength, so that the best measure of prediction, i.e. the estimate of changes in the criterion variable, is attained To completely present the process of analysis and conclusion, the variance analysis is presented below.

Table 20. Additional indicators for the (PA, SN, I)-E multiple regression model

\begin{tabular}{|c|c|c|c|c|c|c|c|c|c|}
\hline \multicolumn{10}{|c|}{ Model Summary $^{\mathrm{d}}$} \\
\hline \multirow[b]{2}{*}{ Model } & \multirow[b]{2}{*}{$\mathrm{R}$} & \multirow[b]{2}{*}{ R Square } & \multirow{2}{*}{$\begin{array}{l}\text { Adjusted R } \\
\text { Square }\end{array}$} & \multirow{2}{*}{$\begin{array}{l}\text { Std. Error of the } \\
\text { Estimate }\end{array}$} & \multicolumn{5}{|c|}{ Change Statistics } \\
\hline & & & & & $\begin{array}{l}\text { R Square } \\
\text { Change }\end{array}$ & F Change & df1 & $\mathrm{df} 2$ & Sig. F Change \\
\hline 1 &, $756^{\mathrm{a}}$ & .571 & .570 & .60417 & .571 & 462.635 & 1 & 347 & .000 \\
\hline 2 & $.812^{\mathrm{b}}$ & .659 & .657 & .53992 & .087 & 88.502 & 1 & 346 & .000 \\
\hline 3 & $.842^{\mathrm{c}}$ & .710 & .707 & .49877 & .051 & 60.449 & 1 & 345 & .000 \\
\hline
\end{tabular}

a. Predictors: (Constant), PA

b. Predictors: (Constant), PA, SN

c) Predictors: (Constant), PA, SN, I

d Dependent Variable: E 
Table 21. Testing the main research hypothesis through step-by-step analysis

\begin{tabular}{|c|c|c|c|c|c|c|}
\hline \multicolumn{7}{|c|}{ ANOVA $^{a}$} \\
\hline \multicolumn{2}{|c|}{ Model } & Sum of Squares & df & Mean Square & $\mathrm{F}$ & Sig. \\
\hline \multirow{3}{*}{1} & Regression & 168.874 & 1 & 168.874 & 462.635 & $.000^{\mathrm{b}}$ \\
\hline & Residual & 126.664 & 347 & .365 & & \\
\hline & Total & 295.538 & 348 & & & \\
\hline \multirow{3}{*}{2} & Regression & 194.674 & 2 & 97.337 & 333.899 & $.000^{\mathrm{c}}$ \\
\hline & Residual & 100.864 & 346 & .292 & & \\
\hline & Total & 295.538 & 348 & & & \\
\hline \multirow{3}{*}{3} & Regression & 209.712 & 3 & 69.904 & 280.995 & $.000^{\mathrm{d}}$ \\
\hline & Residual & 85.827 & 345 & .249 & & \\
\hline & Total & 295.538 & 348 & & & \\
\hline
\end{tabular}

a. Dependent Variable: E

b. Predictors: (Constant), PA

c. Predictors: (Constant), PA, SN

d. Predictors: (Constant), PA, SN, I

Table 22. Testing the model through step-by-step analysis

\begin{tabular}{|c|c|c|c|c|c|c|c|c|c|c|c|}
\hline \multicolumn{12}{|c|}{ Coefficients $^{\mathrm{a}}$} \\
\hline \multirow{2}{*}{\multicolumn{2}{|c|}{ Model }} & \multicolumn{2}{|c|}{$\begin{array}{c}\text { Unstandardized } \\
\text { Coefficients }\end{array}$} & \multirow{2}{*}{\begin{tabular}{|c|}
$\begin{array}{c}\text { Standardized } \\
\text { Coefficients }\end{array}$ \\
Beta
\end{tabular}} & \multirow{2}{*}{ tons } & \multirow{2}{*}{ Sig. } & \multicolumn{2}{|c|}{$\begin{array}{l}95.0 \% \text { Confidence } \\
\text { Interval for B }\end{array}$} & \multicolumn{3}{|c|}{ Correlations } \\
\hline & & B & Std. Error & & & & $\begin{array}{l}\text { Lower } \\
\text { Bound }\end{array}$ & Upper Bound & \begin{tabular}{|c|}
$\begin{array}{c}\text { Zero-ord } \\
\text { er }\end{array}$ \\
\end{tabular} & Partial & Part \\
\hline \multirow{2}{*}{1} & (Constant) & .748 & .144 & & 5.181 & .000 & .464 & 1.032 & & & \\
\hline & PA & .823 & .038 & .756 & 21.509 & .000 & .747 & .898 & .756 & .756 & .756 \\
\hline \multirow{3}{*}{2} & (Constant) & .310 & .137 & & 2.257 & .025 & .040 & .579 & & & \\
\hline & $\mathrm{PA}$ & .468 & .051 & .430 & 9.204 & .000 & .368 & .568 & .756 & .443 & .289 \\
\hline & $\mathrm{SN}$ & .464 & .049 & .440 & 9.408 & .000 & .367 & .562 & .758 & .451 & .295 \\
\hline \multirow{4}{*}{3} & (Constant) & .099 & .130 & & .760 & .448 & -.156 & .353 & & & \\
\hline & $\mathrm{PA}$ & .234 & .056 & .215 & 4.194 & .000 & .124 & .344 & .756 & .220 & .122 \\
\hline & $\mathrm{SN}$ & .309 & .050 & .293 & 6.210 & .000 & .211 & .407 & .758 & .317 & .180 \\
\hline & I & .418 & .054 & .407 & 7.775 & .000 & .312 & .523 & .799 & .386 & .226 \\
\hline
\end{tabular}

a. Dependent Variable: E

The above ANOVA table presents the analysis that offers information about the significance of $F$ statistics, indicating that the null hypothesis, which assumes absence of regression of predictor variables to the criterion variable, may be discarded. This effectively indicates that the main research hypothesis set for this study may be accepted.

Zero-order is the linear correlation between the predictor and criterion variable, while the Partial (pure) correlation between the following predictor and criterion variable, when the correlation of the first (all previous) predictors and the criterion variable is held controlled, i.e. constant, while the size represents the semi-partial correlation that also exhibits satisfactory values. As evident from the above table, the $\mathrm{T}$ statistics is positive and significant for all predictor variables, i.e. their determination coefficients, except for the variables held constant, which was totally expected, but they were not relevant for further analysis for this type of study.
Table 23. Analysis of the residuals of the multiple regression model

\begin{tabular}{|c|c|c|c|c|c|}
\hline \multicolumn{7}{|c|}{ Residuals Statistics $^{\mathbf{a}}$} \\
\hline & Minimum & Maximum & Mean & $\begin{array}{c}\text { Std. } \\
\text { Deviation }\end{array}$ & $\mathrm{N}$ \\
\hline Predicted Value & 1.0593 & 4.9023 & 3.7748 & .77629 & 349 \\
\hline Residual & -1.78370 & 1.60310 & .00000 & .49662 & 349 \\
\hline $\begin{array}{c}\text { Std. Predicted } \\
\text { Value }\end{array}$ & -3.498 & 1.452 & .000 & 1.000 & 349 \\
\hline Std. Residual & -3.576 & 3.214 & .000 & .996 & 349 \\
\hline
\end{tabular}

a. Dependent Variable: E

The above table shows maximum and minimum residual values, their arithmetic means and standard deviations, and, of course, the number of units in the sample. The arithmetic mean of the residuals equals zero, which is necessary in this case, while the arithmetic mean of prediction values has the identical value as the arithmetic mean obtained from empirical data (3.7748). The analysis of the residuals shows that they exhibit a normal distribution. This 
conclusion may be made on the basis of the value of Kurtosis $=.959$, which is lower than 1.96 , but also the value of Skewness=-.347, which is lower than 1.96, so the hypothesis about the normalcy of the residuals is accepted, which satisfies the precondition for application of the regression model. Other preconditions connected with the regression model include meeting the linearity precondition, standard errors cancel each other on average, so that residuals' arithmetic mean is equal to zero and variance is constant. On the basis of all above, it is possible to accept the regression model, both for each individual predictor and for any combinations of them, which proves both the main research hypothesis and the auxiliary ones. This also statistically proves the causal relationship between predictor and the criterion variable in this study.

According to the theoretical framework and this research results it could be seen that similar factors shape behavior of young population but it could be interfere by cultural and political heritage in some countries and regions. During analyzing of entrepreneurial intent in this research it could be seen research corresponding with the earlier research results and theoretical assumptions, but during deeper analysis some of the some specific aspects could be recognized according to the of transition countries substance. That means the socio-cognitive models are universally applicable and especially to the student population such the case of this research in Bosnia and Herzegovina and region. The main limitation of this research is predominant focus on the student of economic and business stream and in the future it could be good to conduct similar research by including students from other scientific background and test their entrepreneurial intentions. For the future research it could be good include some other items and constructs in model that could be involve questions such as cultural, political and traditional values and heritage on entrepreneurial intent. Thus, for instance, it would be useful to test if the people, especially students within societies, whose traditional culture views entrepreneurship unfavorably, launch entrepreneurial undertakings for purely existential reasons, rather than because they perceive a market opportunity or as a chance for their career development. Because Bosnia and Herzegovina and its neighbor countries are for some time, undergoing the process of transition from the socialist towards capitalist economy, i.e. from a collectivist to an individualist mode of thinking, it would be interesting to examine to what extent nowadays traditional values influence entrepreneurial intent of younger people according to the transition of attitudes from older to younger population.

\section{Conclusions}

According to the research results and the main research hypothesis the content and activities of the CEO
Conference shape personal attitudes, social norms and capacity for innovation of the participants, and personal attitudes and have a significant impact on their entrepreneurial orientation and employability. The auxiliary hypotheses, the contents and activities of the CEO conference shape personal attitudes, social norms and their capacity for innovation and has a significant impact on their entrepreneurial orientation and employability, are accepted, according to the statistical analysis. It means that higher-education institution can generate change of students' attitude and motivate them to start up business or proactively find other self-employment perspective. It means that higher-education institution ultimately must obtain, beside conventional content of studying, some additional contents and area for the student that could be shaped by them own in sense to develop their practical skills as an additional component of their total competences that are based on knowledge they have got during their studying process. According to the statistical analysis and proving the hypotheses in practical sense, research that was conducted has led to the conclusion that, along with the process of education in the higher-education institutions, students ought to be offered additional contents that would focus on the development of their competences and skills with the aim to increase the degree of their employability. The concrete research conducted on the sample of the population of students who participated in the CEO Conference and benefited from its various offerings allows us to conclude that events with specially formatted and generated content may have an impact on students' employability, which has been statistically proven. In addition to the statistical component within the framework of this study, a number of practical aspects should be noted. First, the CEO Conference of the Sarajevo University-School of Economics and Business Sarajevo was in its entirety planned and managed by the students of the School of Economics and Business Sarajevo, starting with planning of events and content, securing funding, mobilization of speakers, promotion on social networks, booking premises and planning schedules, as well as other activities required to organize such a demanding event. In addition, as a further practical proof of the stated hypotheses, it should be underlined that in 2011-2017 period, the CEO Conference was led by several teams composed of 10-15 students of the School of Economics and Business Sarajevo from generation to generation in succession extended with the CEO team network from other universities. In direct contacts with these students it was found that all above students were either employed or that they started their own businesses, i.e. were self-employed or they created combined carriers for themselves. This fact is a practical proof that participation in a practical implementation of specific events at higher-education institutions cause that students who actively participate in implementation of such events learn faster than others, which raises their employability to a 
very high level and allows them to choose between two or more offers at their disposal.

Another conclusion that may be proposed concerns the need that higher-education institutions redefine their modus operandi and shift from their conservative bureaucratic stance to the platform of universities of the third, or fourth, generation, which implies application of entrepreneurially oriented format based on the fourth technological revolution. In this context, it is to be expected that research and business projects, involving joint work of professors, students, business community and government representatives to ensure faster development of the economy, technology and society and improved competitiveness in each of these segments in the regional and global context. This approach will ensure a high degree of democratization of society as a whole, with a sustainable system of development based on exploitation of jointly generated innovative solutions. Lastly, a significant fact that provides an additional argument to justify the results obtained through this research that was conducted is found in the participants' demographic characteristics, which clearly display a higher degree of perceived, but real, employability of participants with higher levels of education. The data shows that the participants who completed the third cycle of education constitute a category of people who are fully employed or self-employed, while the descriptive simplified statistics allows a much higher rate of real employability of students in the second-cycle studies relative to participants attending the first-cycle studies and secondary school, thus these fact may be considered as a control framework for the research we conducted

\section{REFERENCES}

[1] Bosma N. The Global Entrepreneurship Monitor (GEM) and Its Impact on Entrepreneurship Research, Foundations and Trends ${ }^{\circledR}$ in Entrepreneurship, Published by: now Publishers Inc. 2013; 9(2):143-248.

[2] Audet J. longitudinal study of the entrepreneurial intentions of university students, Academy of Entrepreneurship Journal, 2004; 10(1): 4-6.

[3] Moriano J. A. Personal Values and Entreprenurial Intentions an Empirical Study, ESU Conference University of Tartu, Estonuia, 2010; 5-7.

[4] Francisco L. Assesing the Stability of Graduates Entrepreneurial Intention and Exploring its Predictive Capacity, Emerald Group Publishing Limited, 2015; 7-9.

[5] Daniela M., Rainer H., Norbert K., Birgit W. W. The impact of entrepreneurship education on the entrepreneurial intention of students in science and engineering versus business Studies University programs, Technological Forecasting \& Social Change 104 2016; 172-179.

[6] Krueger, N. F., Reilly, M. D., \& Carsrud, A.L. Competing
Models of Entrepreneurial Intentions. Journal of Business Venturing, 2000; 15(5-6), 411-432.

[7] Kolvereid, L. \& Isaksen, E. New Business Start-up and Subsequent Entry into Self- employment. Journal of Business Venturing, 2006; 21(6), 866-885.

[8] Jun, Y., Thee Impact of Entrepreneurial Personality Traits on Perception of New Venture Opportunity, New England Journal of Entrepreneurship, 2010; 13(2), 21-35.

[9] Autio, E., Keeley, R.H., Klofsten, M., Parker, G.C., \& Hay, M. Entrepreneural Intent among Students in Scandinavia and in the USA. Enterprise and Innovation Management Studies, 2001; 2(2), 145-160.

[10] Kolvereid, L. Prediction of employment status choice intentions, Entrepreneurship Theory and Practice, 21(1), 1996; 47-58.

[11] Krueger, N. F. Jr., Reilly, M. D., Carsrud, A. L. (2000). Competing models of entrepreneurial intentions. Journal of Business Venturing, 15, 411- 432.

[12] Kolvereid, L. \& Isaksen, E. New business start-up and subsequent entry into self-employment. Journal of Business Venturing, 2006; 21(6), 866-885.

[13] Liñán, F., Nabi, G., \& Krueger, N. British and Spanish Entrepreneurial Intentions: A Comparative Study-Revista de Economía Mundial, 2013; 33, 73-103.

[14] Liñán F., Chen Yi-Wen, Development and Cross-Cultural Application of a Specific Instrument to Measure Entrepreneurial Intentions, Entrepreneurship Theory and Practice, 2009; 593-617.

[15] Ajzen, I. Perceived behavioral control, self-efficacy, locus of control, and the theory of planned behavior. Journal of Applied Social Psychology, 2002; Vol. 32, No. 4, 665-683.

[16] Luluk T. H., Achmad S., Mintarti R., Achmad F. Study of the Bandura's Social Cognitive Learning Theory for the Entrepreneurship Learning Proces, Science PG, 2017; 1-7.

[17] Čizmić E., Kanita I. Č., The Principles of Third Generation Universities Functioning-Lessons for Universities in Transition Process; Periodical for social Issues, Sarajevo University, 2013; 51-70.

[18] Duijin, Wouter, Entrepreneurial Intentions among FDEWB Students, 2015, 37. 